\title{
A parametric fault displacement model to introduce kinematic control into modeling faults from sparse data
}

\author{
Gabriel Godefroy ${ }^{1}$ (gabriel.godefroy@univ-lorraine.fr), \\ Guillaume Caumon ${ }^{1}$, Mary Ford ${ }^{2}$, \\ Gautier Laurent ${ }^{1}$, Christopher A.-L. Jackson ${ }^{3}$,
}

Author version. Accepted in Interpretation https://doi.org/10.1190/int-2017-0059.1

Reuse is subject to SEG terms of use and conditions.

\section{Abstract}

Fault-related displacements impact oil and gas flow predictions at reservoir scales. In this contribution, we integrate a quantitative description of fault-related deformation directly embedded into the structural modeling workflow. Consistent fault displacements are produced by using numerical fault operators that deform horizons in accordance with theoretical isolated fault displacement models to generate kinematically consistent structural models.

We compare structural modeling approaches based on such fault operators with those relying on interpolation. Several synthetic cross-sections are generated from a reference high-resolution structural model of the Santos Basin, Brazil. Models are reconstructed from this $2 \mathrm{D}$ synthetic sparse dataset using both methods. Their ability to produce consistent structural models is assessed by comparing reconstructed and reference models. On this example, kinematic modeling improves the quality of automatically generated models when only few and poor quality observations are available, thus reducing the time needed for structural validation.

\footnotetext{
${ }^{1}$ GeoRessources, Université de Lorraine/CNRS/CREGU, 2 Rue du Doyen Marcel Roubault, 54500 Vandoeuvre-lès-Nancy, France

${ }^{2}$ CRPG, UMR 7358, Université de Lorraine, 15 Rue Notre Dame des Pauvres, 54501 Vandoeuvre-lès-Nancy, France

${ }^{3}$ Basins Research Group (BRG), Department of Earth Science and Engineering, Imperial College, Prince Consort Road, London SW7 2BP, UK
}

\section{Introduction}

The physical properties and geometry of near-fault stratigraphic units are used by most fault-seal algorithms (e.g., Jolley et al., 2007; Manzocchi et al., 2010). However, the distributed damage associated with faulting perturbs the seismic imaging of faults (Sibson, 1977; Botter et al., 2014; Iacopini et al., 2016; Weinzierl et al., 2016; Botter et al., 2017) and the nearfault geometry is generally poorly constrained. This leads to uncertainties in oil and gas flow simulations and volume assessments (Hollund et al., 2002; Thore et al., 2002; Rivenæs et al., 2005; Richards et al., 2015).

Classically, structural surfaces are built by interpolating fault and horizon points picked on seismic data but this method does not explicitly constrain modeled fault displacements. Several methods also exist to estimate fault geometry from seismic images based on semblance (e.g., Machado et al., 2016; Qi et al., 2017; $\mathrm{Wu}$ and Zhu, 2017). Image warping methods can also estimate fault throw (Hale, 2013), but may be limited by the seismic resolution and the quality of the seismic image. In all cases, the kinematic consistency of the resulting structural models then needs to be tested using rules such as displacement distance characteristics (Chapman and Meneilly, 1990), visual inspection of displacement profiles and maps (Freeman et al., 1990), by empirically assessing the strain in rocks adjacent to faults (Freeman et al., 2010) or by using restoration (Maerten and Maerten, 2015). After this quality control, it is often necessary to add or manually move interpolation points until a valid geometry of the nearfault stratigraphy is obtained. As a result, significant time is spent moving back and forth between structural interpretation, modeling and validation. This quality control loop increases the time required to obtain a valid model (Caumon et al., 2013b). 
Barnett et al. (1987) and Freeman et al. (1990) suggest using a model of fault displacement while interpreting and building 3D faulted models. The displacement on the fault surface is assumed to be maximum near the fault center, and to decrease slowly toward an ellipsoidal fault tip line (Figure 1.a,b). This theoretical displacement distribution is widely accepted for isolated blind normal faults (Walsh and Watterson, 1987, 1988, 1989; Nicol et al., 1996; Kim and Sanderson, 2005; Osagiede et al., 2014) and has been used to validate or to create valid interpretations of poorly seismically imaged isolated faults (Chapman and Meneilly, 1990; Freeman et al., 1990). Several authors have also integrated fault kinematics, i.e., the distribution of the slip on and close to the fault surface, directly into the modeling process. In these approaches, the slip distribution is expressed by a numerical fault operator (Munthe et al., 1994; Hollund et al., 2002; Holden et al., 2003; Georgsen et al., 2012; Laurent et al., 2013).

Such kinematic fault operators have demonstrated their applicability to the modeling of synthetic (Munthe et al., 1994; Georgsen et al., 2012; Laurent et al., 2013) and real (Hollund et al., 2002; Holden et al., 2003) faulted structures. Our three-dimensional fault operator extends the work of Laurent et al. (2013) and Georgsen et al. (2012). It deforms a first approximated continuous horizon geometry along faultparallel lines in the dip directionusing a 3D discontinuous displacement field. The displacement magnitude is controlled by a given maximum slip length and three parametric profiles. Instead of manually adjusting the parameters of the fault operator, we use numerical optimization to match available horizon data as in Allmendinger (1998); Cardozo and Aanonsen (2009); Cardozo et al. (2011) and Cardozo and Brandenburg (2014). Our fault operator is thus consistent with fault geometries, horizon observations and theoretical displacement models. Thanks to this kinematic fault operator, a theoretical displacement distribution can be used to generate realistic faulted models and facilitate the model validation, especially when only few or poor quality data are available.

In this paper, we compare our kinematic modeling method with an approach that relies on interpolation only to model horizon geometries. Interpretations along synthetic parallel 2D seismic cross-sections were extracted from a reference model built from high resolution 3D seismic data from the Santos Basin, offshore Brazil. Two structural models are reconstructed using both modeling methods from these synthetic sparse data. We show that, in the case of sparse data, our operator improves the consistency of horizon geometries near faults. The fault operator produces a consistent slip distribution even from sparse observations and filters noise in the input data.

\section{Kinematic modeling}

\subsection{Fault near-field and far-field displace- ment}

The displacement associated with faults can conceptually be separated into a near-field component and a far-field component (Barnett et al., 1987). The near-field displacement represents the discontinuous displacement in the volume immediately surrounding the fault surface. The far-field displacement is the regional contribution of the fault to the bulk displacement (Laurent et al., 2013). Geologists who predict hydrocarbon production focus on near-fault geometries because most of fault-seal related algorithms rely on displacements to model fault transmissivities (e.g., Jolley et al., 2007; Manzocchi et al., 2010).

Displacement is usually quantified on the fault surface using displacement vectors (Liang et al., 2010; Hale, 2013), displacement maps (Freeman et al., 2010; Tvedt et al., 2013, 2016) or throw profiles along strike or down-dip (Willemse, 1997; Peacock, 2002; Nixon et al., 2011; Jackson and Rotevatn, 2013; Magee et al., 2015). However, the near-field displacement is not only expressed by the slip along the fault surface (Figure 1.b), but also by the displacement in the surrounding stratigraphy (Figure 1.c). In the direction orthogonal to the fault surface, flanking structures (due for instance to fault drag or fault-related folding) have been observed (Chapman and Meneilly, 1990; Grasemann et al., 2005; Coelho et al., 2005; Mulchrone, 2007; Spahić et al., 2013; Mukherjee, 2014). These orthogonal structures coupled with the observations close to the fault surface have been used to propose threedimensional parameterizations of the fault-related displacement (Georgsen et al., 2012; Laurent et al., 2013).

\subsection{Kinematic fault operators for struc- tural modeling}

Kinematic fault operators are 3D numerical objects that are designed for deforming geological strata in accordance with theoretical displacement patterns. They represent not only the fault geometry but also the displacement, which is integrated through the fault operator. Such operators have been proposed for modeling 


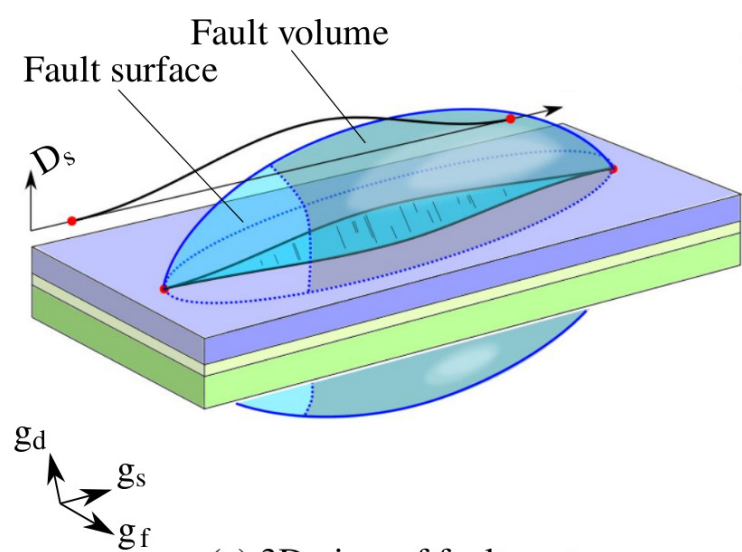

(a) $3 \mathrm{D}$ view of fault anatomy

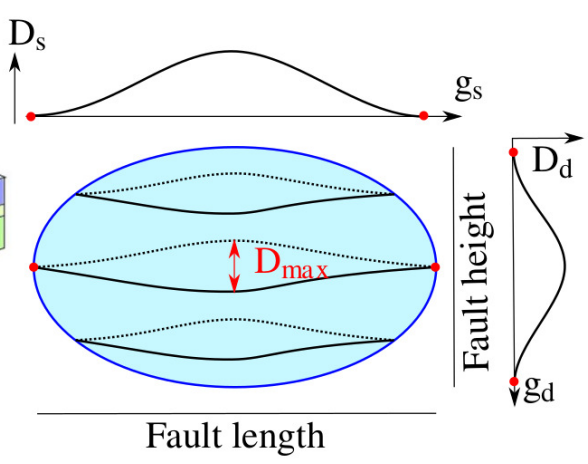

(b) Elliptical fault surface

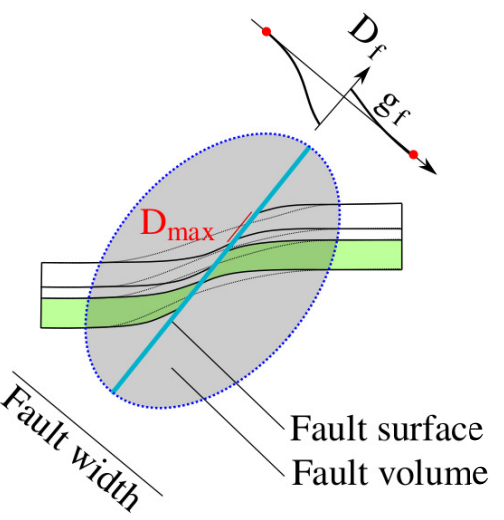

(c) Cross-section view

Figure 1: The slip associated with a theoretical isolated normal fault can be described using a maximum displacement $\mathbf{D}_{\max }$ and three displacement profiles: $D_{s}, D_{d}$ and $D_{f}$. (a) $3 \mathrm{D}$ view. The axes of the local fault space $\left(g_{s}, g_{d}\right.$ and $\left.g_{f}\right)$ are aligned with the fault strike, the fault dip and normal to the fault surface. (b) Slip on the fault surface, described using $D_{s}$ and $D_{d}$. (c) Slip attenuation in the direction orthogonal to the fault surface $\left(D_{f}\right)$.

reservoirs with subseismic faults (Munthe et al., 1994; Hollund et al., 2002), for easily modifying reservoir models in stochastic modeling (Holden et al., 2003; Georgsen et al., 2012), and for taking geological history into account during model construction (Laurent et al., 2013).

Georgsen et al. (2012) and Laurent et al. (2013) implement fault operators where fault geometry and slip are modeled according to the description of Barnett et al. (1987). The three-dimensional displacement is modeled parallel to the fault surface. Georgsen et al. (2012) compute the intensity of the displacement by kriging the slip on the fault surface. The kriging has an external drift to take into account the elliptical shape of the displacement in the fault plane (Walsh and Watterson, 1989). An orthogonal profile is used to extrapolate the displacement away from the fault. Laurent et al. (2013) use three slip-profiles and the length of the slip at the fault center to describe the displacement. They apply the displacement using a shape deformation method computed within a 3D curvilinear fault space aligned on the fault surface.

One limitation for effectively using these operators is the difficulty in fitting horizon observations. Georgsen et al. (2012) propose to krige fault slip measured from observed fault cutoff lines to honor horizon geometry on the fault plane. However, the difficulty in imaging the near-fault displacement (Figure 2) usually makes such slip measurements highly uncertain. We propose using data located not only on the fault surface but also in the volume surrounding the fault (near-fault

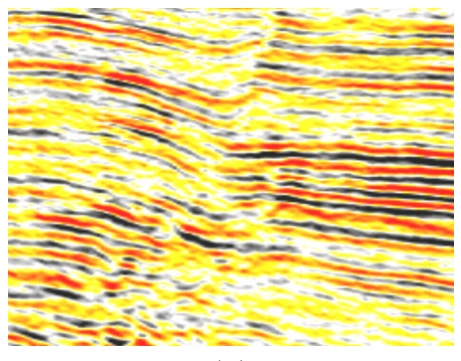

(a)

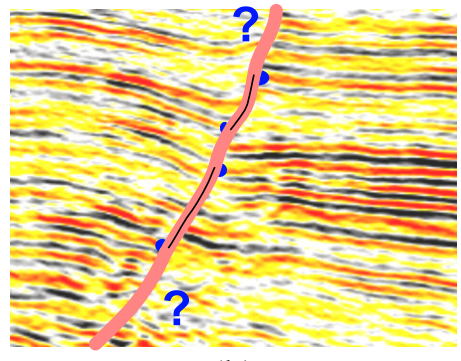

(b)
Figure 2: The seismic reflectors are blurred close the fault surface. Determining the intersections between fault and horizons in the hanging wall and in the footwall is not straightforward (Weinzierl et al., 2016) and slip measurements on the fault surface are usually highly uncertain. (a) Input seismic image. (b) Slip measurements are possible only where the seismic reflectors quality is good enough.

observations) to better constrain displacement on the fault surface.

\subsection{Conditioning a parametric fault dis- placement operator to near-fault ob- servations}

\section{Proposed conceptual fault model}

In this section, we introduce a new fault operator which takes advantage of both approaches proposed by Georgsen et al. (2012) and Laurent et al. (2013). The fault geometry is represented by a surface bounded by an elliptical tip line (Figure 1.a). The fault displace- 

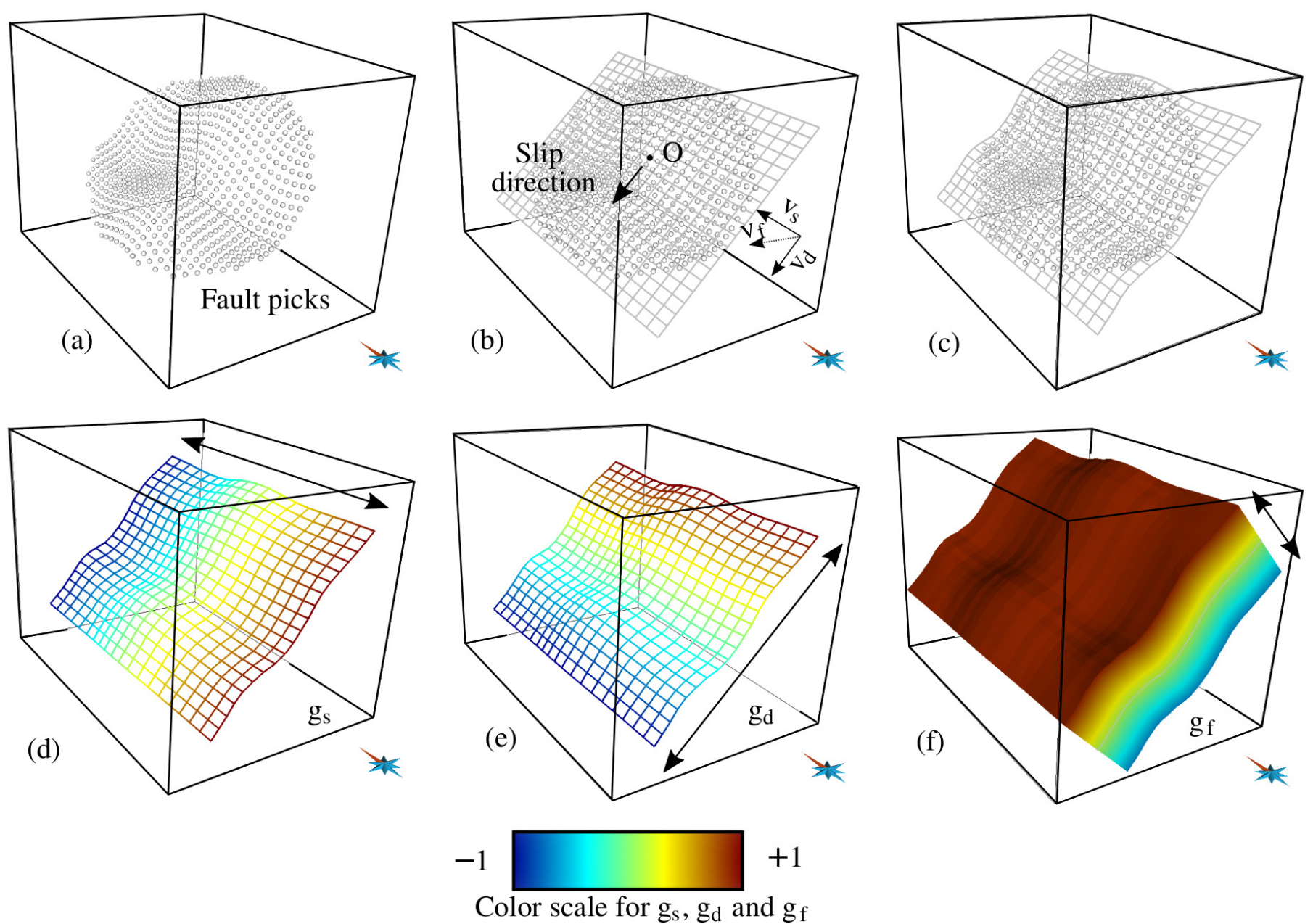

Figure 3: (a) Input fault picks. (b) Regular grid computed from medium fault plane and aligned with the slip direction. (c) Fault geometry interpolated on the regular grid. (d,e,f) $\mathbf{G}_{\mathbf{F}}=\left\{g_{s}, g_{f}, g_{d}\right\}$ defines a local fault space.

ment is modeled within an ellipsoidal volume, also called the fault operator volume in this article. The displacement is discontinuous across the fault surface and decreases smoothly from a point of maximum displacement located at (or near to) the fault center toward the envelope of the fault operator volume (Figure 1.c). The displacement is parallel to the fault surface and is purely dip-slip.

\section{Fault geometry and local fault space $G_{F}$}

We describe the fault geometry using a regularly gridded surface. The grid is located at the medium plane computed from interpreted fault picks (Figure 3.a). It is oriented using the slip vector (Figure 3.b). The distance between this medium plane and the fault surface is interpolated between the fault picks (Figure 3.c), as proposed in Georgsen et al. (2012). Formally, the regular grid representing the medium fault plane is defined by three unit vectors $\left\{v_{s}, v_{f}, v_{d}\right\}$ (aligned on the fault strike, dip and normal direction, respectively) and an origin $\mathbf{O}=\left\{o_{x}, o_{y}, o_{z}\right\}$.

The distance from a point $\mathbf{X}=\{x, y, z\}$ to the fault center can be measured in three directions: along strike $g_{s}(\mathbf{X})$ (Figure 3.d), along dip $g_{d}(\mathbf{X})$ (Figure 3.e), and orthogonally to the fault surface $g_{f}(\mathbf{X})$ (Figure 3.f). These coordinates are used to define a local fault space $\mathbf{G}_{\mathbf{F}}=\left\{g_{s}, g_{f}, g_{d}\right\}$ and are normalized using the fault length, height and width in order to be 0 at the fault center and so that $\left\|\mathbf{G}_{\mathbf{F}}\right\|=1$ at the limit of the fault operator volume. This local fault space $\mathbf{G}_{\mathbf{F}}$ is used to define a signed distance function $d=f\left(g_{s}, g_{d}\right)$ between the surface and the medium plane (Figure 3.c). The coordinates of a point $\mathbf{X}=\{x, y, z\}$ within $\mathbf{G}_{\mathbf{F}}=$ $\left\{g_{s}, g_{f}, g_{d}\right\}$ are computed using:

$$
\left(\begin{array}{l}
g_{s} \\
g_{f} \\
g_{d}
\end{array}\right)=\left[\begin{array}{lll}
v_{s} & v_{f} & v_{d}
\end{array}\right]\left(\begin{array}{l}
x-o_{x} \\
y-o_{y} \\
z-o_{z}
\end{array}\right)+\left(\begin{array}{c}
0 \\
d\left(g_{s}, g_{d}\right) \\
0
\end{array}\right) .
$$


A second coordinate system $\mathbf{G}_{\mathbf{F}}^{\mathbf{n}}=\left\{g_{s}^{n}, g_{f}^{n}, g_{s}^{n}\right\}$ is also defined so that $\mathbf{G}_{\mathbf{F}}^{\mathbf{n}}$ coordinates are normalized between -1 and 1 in the ellipsoidal fault operator volume:

$$
g_{i}^{n}=\frac{g_{i}}{\sqrt{\left(g_{i}\right)^{2}+1-\text { norm }^{2}(g)}}, i=s, f, d,
$$

with $\operatorname{norm}^{2}(g)=\left(g_{s}\right)^{2}+\left(g_{f}\right)^{2}+\left(g_{d}\right)^{2}$.

\section{Fault displacement}

The fault displacement is parameterized by the maximum displacement $\mathbf{D}_{\max }$ and three profiles (Figure 1): along-dip $D_{d}$, along-strike $D_{s}$, (also called displacement-distance by Nixon et al. (2011) and throw-distance profiles by Tvedt et al. (2016)), and across-fault $D_{f}$ profiles. Structural geologists use along-strike and along-dip profiles to: (1) study fault displacement versus length scaling laws (Kim and Sanderson, 2005), (2) distinguish post- and syn-sedimentary faults (Baudon and Cartwright, 2008) and investigate fault growth history (Giba et al., 2012), and (3) guide the interpretation of faulted structures when little data is available (Barnett et al., 1987; Freeman et al., 1990),

In the vicinity of the fault surface, strata are deflected and rotated, forming flanking-structures. Parametric descriptions of flanking structures (Coelho et al., 2005; Mukherjee, 2014) and analytical modeling of fault drag (Grasemann et al., 2005) have been proposed. We call $D_{f}$ the orthogonal displacement profile that can be used to describe these structures. Formally, this third profile describes how the displacement is attenuated when moving away from the fault surface (Figure 1.b).

\section{Displacement magnitude.}

The profiles used by our operator are parametric Hermite splines that are constrained so that the gradient of $D_{f}$ is null at the limit of the fault operator volume because the displacement decreases smoothly away from the fault plane. The fault dies out where the displacement is null so $D_{s}$ and $D_{d}$ are null on the fault envelope. In the simplest (isolated fault) case, $D_{s}$ and $D_{d}$ are continuous with maximum values near the fault center (Figure 4.a). The $D_{f}$ profile (orthogonal to the fault) is discontinuous on 0 to account for the discontinuity of the deformation field across the fault. $D_{f}$ can be asymmetric to account for the asymmetry commonly observed in the brittle fault damage zone

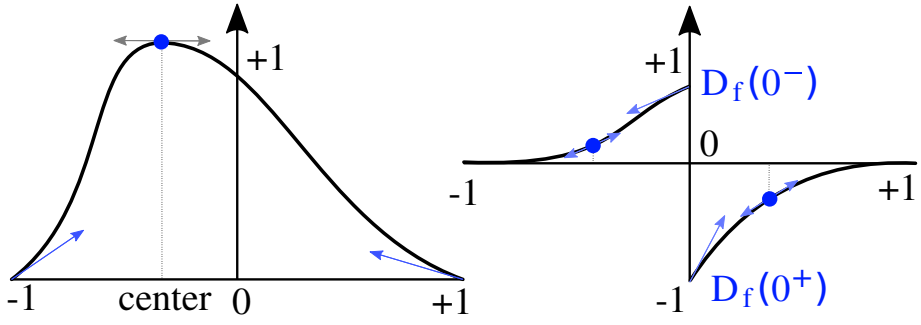

(a)

(b)

Figure 4: Parametric throw profiles defined using two Hermite splines (modified from Laurent et al. (2013)). (a) Theoretical model for $D_{s}$ and $D_{d}$. (b) Theoretical model for $D_{f}$. Scalar parameters that are optimized in our implementation are shown in blue.

(e.g., Berg and Skar, 2005). (Figure 4.b). The displacement magnitude is computed using these profiles and the distances to the fault center $\left(g_{s}\right.$ and $\left.g_{d}\right)$ and to the fault surface $\left(g_{f}\right)$ :

$$
\mathbf{D}_{\text {operator }}(\mathbf{X})=\mathbf{D}_{\max } * \operatorname{att}(\mathbf{X})
$$

where the attenuation $\operatorname{att}(\mathbf{X})$ is:

$$
\operatorname{att}(\mathbf{X})=D_{s}\left(g_{s}^{n}(\mathbf{X})\right) * D_{f}\left(g_{f}^{n}(\mathbf{X})\right) * D_{d}\left(g_{d}^{n}(\mathbf{X})\right) .
$$

\section{Applying displacement.}

Each point $\mathbf{X}^{\text {init }}=\left\{x^{i}, y^{i}, z^{i}\right\}$ of the horizons are deformed within $\mathbf{G}_{\mathbf{F}}$. The first step is to compute the distance to the fault surface, and to determine the $\mathbf{G}_{\mathbf{F}}$ coordinates of the point $\mathbf{X}^{\text {init }}$ (Figure 5, step 1). Within $\mathbf{G}_{\mathbf{F}}$, the displacement is applied using (Figure 5, step 2):

$$
g_{d}^{f}=g_{d}^{f}+\mathbf{D}_{\text {operator }}(\mathbf{X}) .
$$

Finally, we compute $\mathbf{X}^{\text {final }}=\left\{x^{f}, y^{f}, z^{f}\right\}$ from $\mathbf{G}_{\mathbf{F}}$ coordinates (Figure 5, step 3):

$$
\left(\begin{array}{l}
x^{f} \\
y^{f} \\
z^{f}
\end{array}\right)=\left[\begin{array}{lll}
v_{s} & v_{f} & v_{d}
\end{array}\right]^{-1}\left(\begin{array}{c}
g_{s}^{f} \\
g_{f}^{f} \\
g_{d}^{f}
\end{array}\right)+\left(\begin{array}{c}
-o_{x} \\
d\left(g_{s}^{f}, g_{d}^{f}\right)-o_{y} \\
-o_{z}
\end{array}\right) .
$$

\section{Illustrations of the operator capabilities}

The capabilities of our operator are illustrated by deforming initial layer cake models (Figure 6.a,f). As explained before, the fault-related deformation model described by Barnett et al. (1987) can be obtained (Figure 6.b). This simple displacement model is designed 


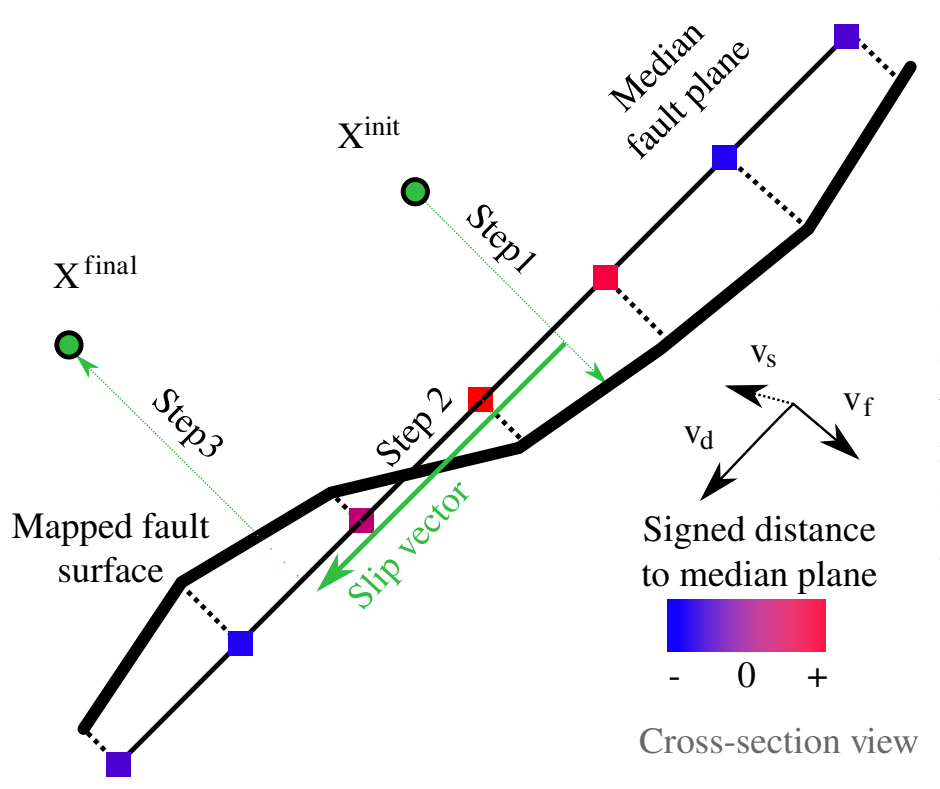

Figure 5: Cross-section through the fault, illustrating how displacement is applied in three steps (modified from Georgsen et al. (2012)). Step 1: the distance to the fault surface (heavy black line) and the $\mathbf{G}_{\mathbf{F}}$ coordinates are computed. Step 2: $g_{d}$ is incremented to account for dip-slip displacement (green vector). Step 3: going back to $\mathbf{X}=\{x, y, z\}$ coordinate space.

for normal faults interacting little with other structures (Barnett et al., 1987). In the case of mechanical layering and soft- or hard-linkage between several faults, displacement patterns can become complicated (e.g., Nixon et al., 2014). Our operator can account for such complexity by adapting the $D_{s}$ profile (Figure 6.c), for example with two slip maxima.

Faults that are larger than the model volume can be represented (Figure 6.d). The parameterization of the fault geometry also enables the modeling of listric faults (Figure 6.e). As the operator applies a displacement parallel to the fault geometry, a fault-bend fold formed over a thrust fault with a flat-ramp geometry can also be obtained (Figure 6.f,g).

\section{Handling syn-sedimentary faults}

Syn-sedimentary faults can affect sediment deposition. Syn-faulting (or growth) layers are thicker on the hanging wall compared to the footwall across normal faults (Figure 7.a). The thickness difference is quantified by the expansion index (EI, Figure 7.b) defined as the ratio between hanging wall ( $\left.H W_{\text {thickness }}\right)$ and footwall (FW thickness $)$ thicknesses (Fossen, 2016;
Tvedt et al., 2016; Jackson et al., 2017):

$$
E I=\frac{H W_{\text {thickness }}}{F W_{\text {thickness }}} .
$$

The expansion index and the slip-depth profile (Figure 7.c) record the variations of the fault activity. The depth profile $\left(D_{d}\right)$ integrates the syn-sedimentary and the mechanical components of fault growth. As a result, our operator can be used not only for blind faults, but also to forward model a syn-sedimentary growth structure from an initial layer cake geometry (Figure 7.d,e).

\section{Limitations}

The displacement direction we model is always parallel to the slip at the fault center. However, slip direction is not always parallel to fault dip. Slip vectors can be oblique near the tips of faults (Roberts, 1996; Roberts and Ganas, 2000) as indicated by striated fault surfaces. While this kind of behavior can be modeled with the operator proposed by Laurent et al. (2013), it is not supported by our implementation. This limitation is mitigated by the fact that a similar final geometry can be obtained by our approach. This simplification also dramatically improves the efficiency of the algorithm in terms of computation time.

The displacement distribution on the fault surface is designed for isolated faults (Barnett et al., 1987). Soft-interaction between faults, also described as kinematic linkage as distinct from geometric linkage (Freitag et al., 2017), generally results in asymmetric displacement with steep displacement gradient close to fault tips (Peacock and Sanderson, 1991; Nixon et al., 2014). This can be handled by using asymmetric $D_{s}$ and $D_{d}$ profiles. However, in the case of fault branching, our implementation cannot currently generate a displacement field parallel to both fault surfaces. It is thus not possible to model the displacement along branch-lines.

The ductile deformation associated with fault structures, as well as the brittle fault damage zone, are generally asymmetric (e.g., Berg and Skar, 2005). In the presented operator, the volume where the ductile deformation is modeled is a symmetric ellipse centered on the fault surface (as in Georgsen et al., 2012). However, our fault model can account for such an asymmetry by using an asymmetric across-fault profile $D_{f}$ (Figure 1.c).

The length and the height of the fault can be deduced from fault picks and constrained by published 

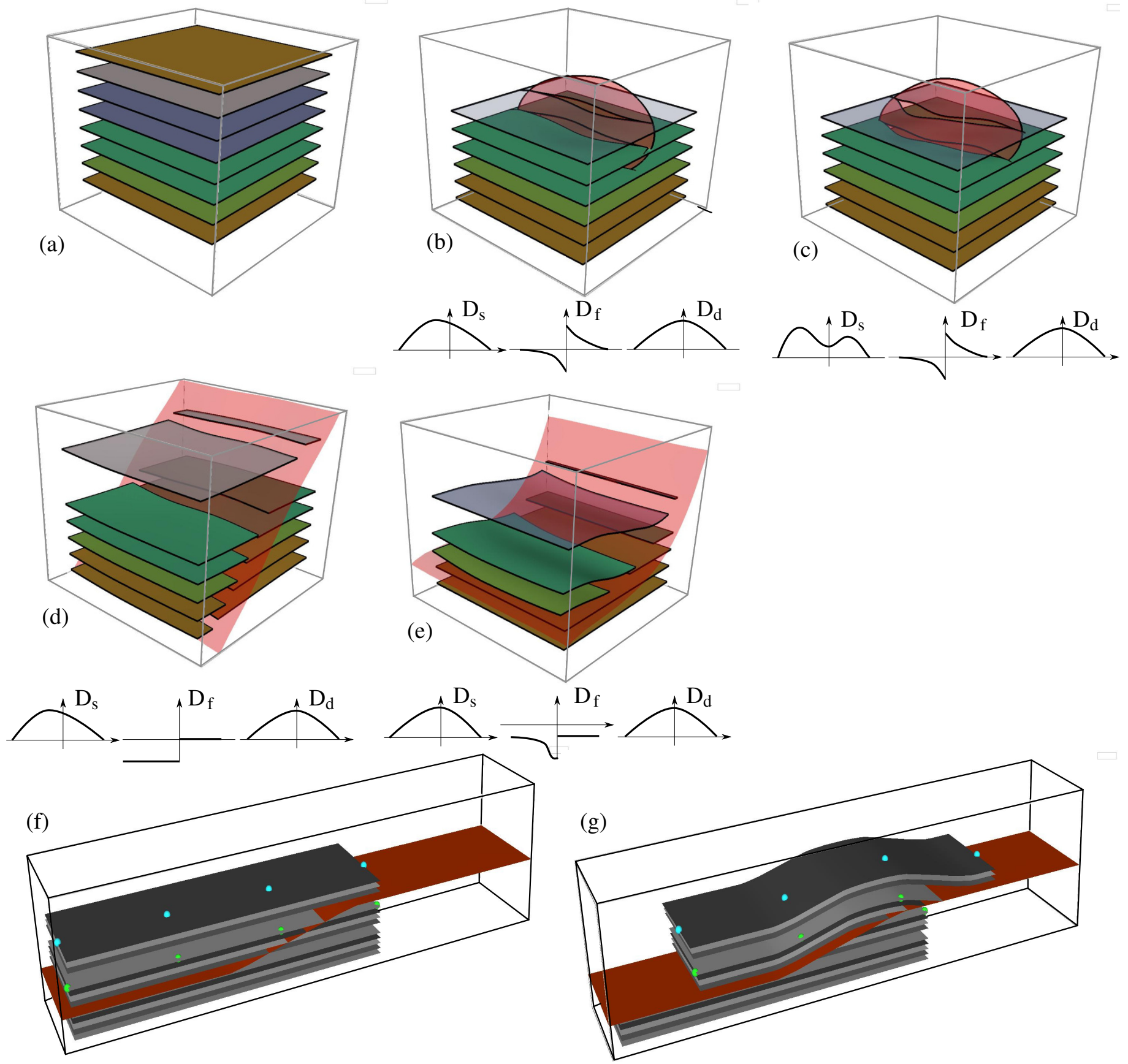

Figure 6: Example of faulted horizons that can be obtained using the operator from a layer cake model (a) and (f). (b) Isolated normal fault with bell-shaped profile. (c) Composite normal fault: $D_{s}$ profile has two local maxima. (d) Infinite normal fault (regarding the extension of the model). $D_{f}$ profile does not decrease away from the fault surface. (d) Listric normal geometry for the fault. No motion in the hanging wall where $D_{f}$ is null. (f) Fault-bend fold formed over a thrust-fault with a flat-ramp-falt geometry. Material is transported parallel to the fault forcing the horizons into an antiformal geometry. 
(a)

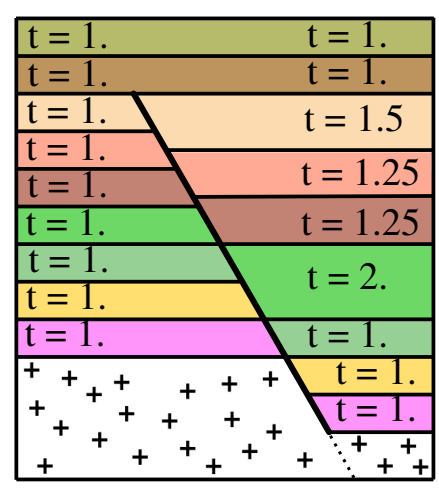

(b)

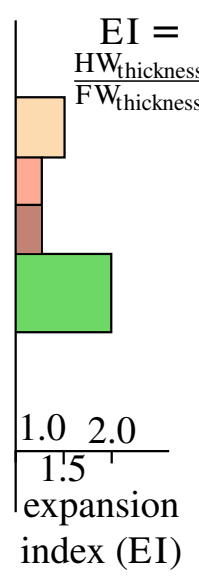

(c)

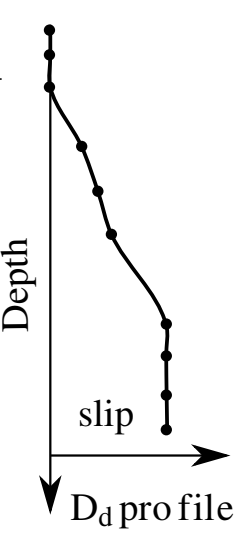

(d)

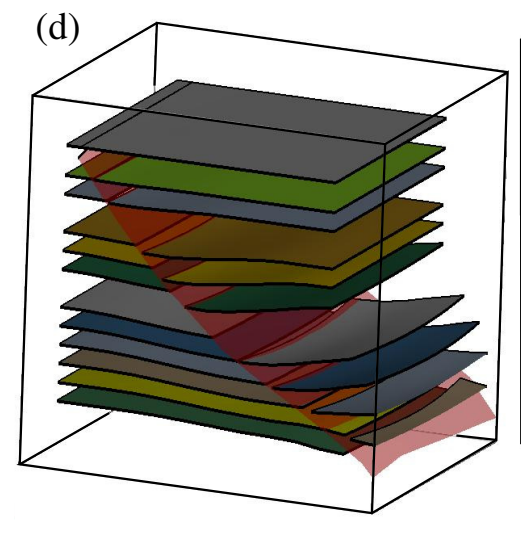

(e)

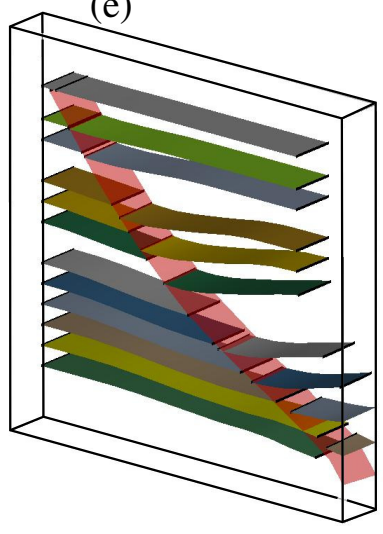

Figure 7: (a) Cross-section through a syn-sedimentary sequence (modified from Fossen (2016)). (b) The Expansion Index (EI) is the ratio between hanging wall $\left(H W_{\text {thickness }}\right)$ and footwall $\left(F W_{\text {thickness }}\right)$ thicknesses. (c) Slip-profile for the syn-sedimentary sequence. The slope of the profile is not-null within syn-sedimentary layers. (d) Three-dimensional model built using our operator from an initial layer cake sequence. The $D_{d}$ profile used is the one shown in (c). (e) Cross-section through model (d).

scaling laws between fault length and maximum displacement (e.g., Nicol et al., 1996; Torabi and Berg, 2011). Choosing the width of the fault operator is more subjective. Childs et al. (2009) noticed the lack of scaling laws integrating the width of the zone of normal drag adjacent to a fault. This width can probably be related to the width of the brittle damage zone and thus to the maximum displacement using previously published scaling laws (e.g., Torabi and Berg, 2011; Johri et al., 2014; Choi et al., 2016).

\subsection{Modeling workflow}

\section{Automatic data fitting using numerical opti- mization}

The main limitation to the interactive use of the previously proposed fault operators is to find appropriate parameters to honor horizon data. Allmendinger (1998); Cardozo and Aanonsen (2009) and Cardozo and Brandenburg (2014) find the best set of parameters for trishear algorithms using numerical optimization. Similarly, the kinematic parameters of our operator are chosen by Particle Swarm Optimization (Eberhart and Kennedy, 1995), a derivative-free optimization method. The cost function to be minimized is the misfit between the observed data and the built model. More precisely, 13 scalar parameters are optimized (shown in blue, Figure 4): (1) the position of the maximum and two tangents for $D_{s}$ and $D_{d}$ (Figure 4.a), (2) the positions of two inflexion points and four tangents for $D_{f}$ (Figure 4.b), and (3) the maximum slip magnitude. In our parallel implementation, the optimization time to find these 13 kinematic parameters is around 5 seconds (on a portable workstation with a processor Intel $(R)$ Core (TM) i7-4510U clocked at $2.00 \mathrm{GHz}$ and $16 \mathrm{~GB}$ of Random-Access Memory).

We propose a 4-step workflow to model faulted structures while honoring horizon picks:

1. The elliptical fault geometries are defined (Figure 8.b). The length, height and position of the centers of the faults are chosen from fault picks, defining the elliptical fault tip-lines. The width of the fault operator is chosen by the user.

2. A first continuous geometry for the horizons is computed. The horizon data within the fault operator volume (i.e., affected by fault displacement) are not taken into account. The whole stratigraphic pile is interpolated using an implicit method (Caumon et al., 2013a). Smooth and continuous horizons separating roughly isopach non-growth strata are obtained (Figure 8.c).

3. Displacement profiles for each fault are computed using Particle Swarm Optimization (Figure 8.d,e). The distances measured between the continuous horizon geometries and the observed horizon picks are used to constrain the optimization. The misfit function corresponds to the dif- 
ference between the measured and the modeled displacement:

$$
\sum_{\text {horizon picks }}\left|\mathbf{D}_{\text {operator }}(\mathbf{X})-\mathbf{D}_{\text {measured }}(\mathbf{X})\right|
$$

4. The fault operator is applied to the continuous stratigraphic pile to add the near-field fault displacement (Figure 8.f).

Thanks to this geometric construction, the horizon is modeled as a continuous surface affected by discontinuous displacement for each fault.

\section{Comparison of modeling strate- gies for near-fault geometries}

To assess the value of introducing kinematic control into modeling faults, we compare the use of our operator with a modeling method relying on implicit surface interpolation (Structure and Stratigraphy workflow from SKUA-GOCAD, Paradigm) to model faulted structures from sparse data. We highlight the benefits and drawbacks of each modeling strategy.

\subsection{Comparison methodology}

\section{Reference model}

In this study, we use a 3D seismic reflection data set from the São Paulo Plateau, Santos Basin, offshore Brazil. The Santos Basin formed as a rift during Early Cretaceous when the South Atlantic began to open. The studied faults developed from Albian to Miocene and from Oligocene to present within Albian Carbonates (Ithanhaem Formation) and within Cenomian-toRecent fine-grained clastics (Itajai-Acu and Marambia formations). The fault activity is linked to the remobilization of the underlying salt anticlines and salt plateaux of the thick (2.4 to $2.6 \mathrm{~km})$ salt-rich unit (Ariri Formation) (see Tvedt et al. (2016) and references therein).

Faults and horizons are imaged using time-migrated 3D seismic reflection data (Figure 9.a). We modeled 27 faults and 12 horizons thanks to the exceptional quality of seismic data in a densely faulted area to build our reference model (Figure 9.b,c).
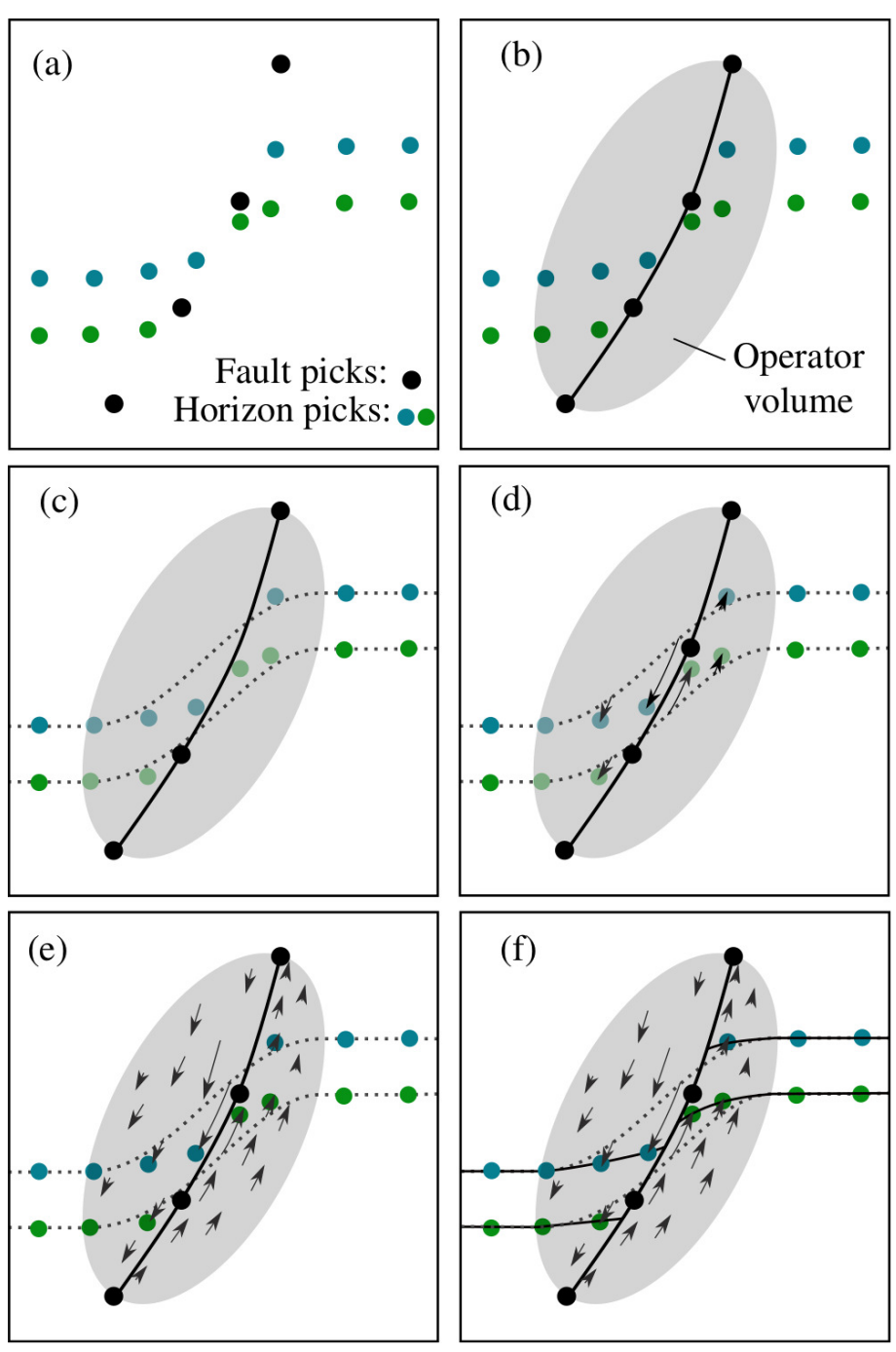

Figure 8: Kinematic modeling workflow, illustrated on a vertical cross-section. (a) Input fault and horizon picks. (b) The geometry of the fault (black line) is built from fault picks. Near-field fault volume is shown is grey. (c) A first continuous horizon geometry (dashed line) is built using only horizon observations away from the fault. (d) Distances between this geometry and horizon observations near the fault are computed. (e) The distances are used to parameterize the fault operator. (f) The fault operator is applied to the horizons to build the structural model. 


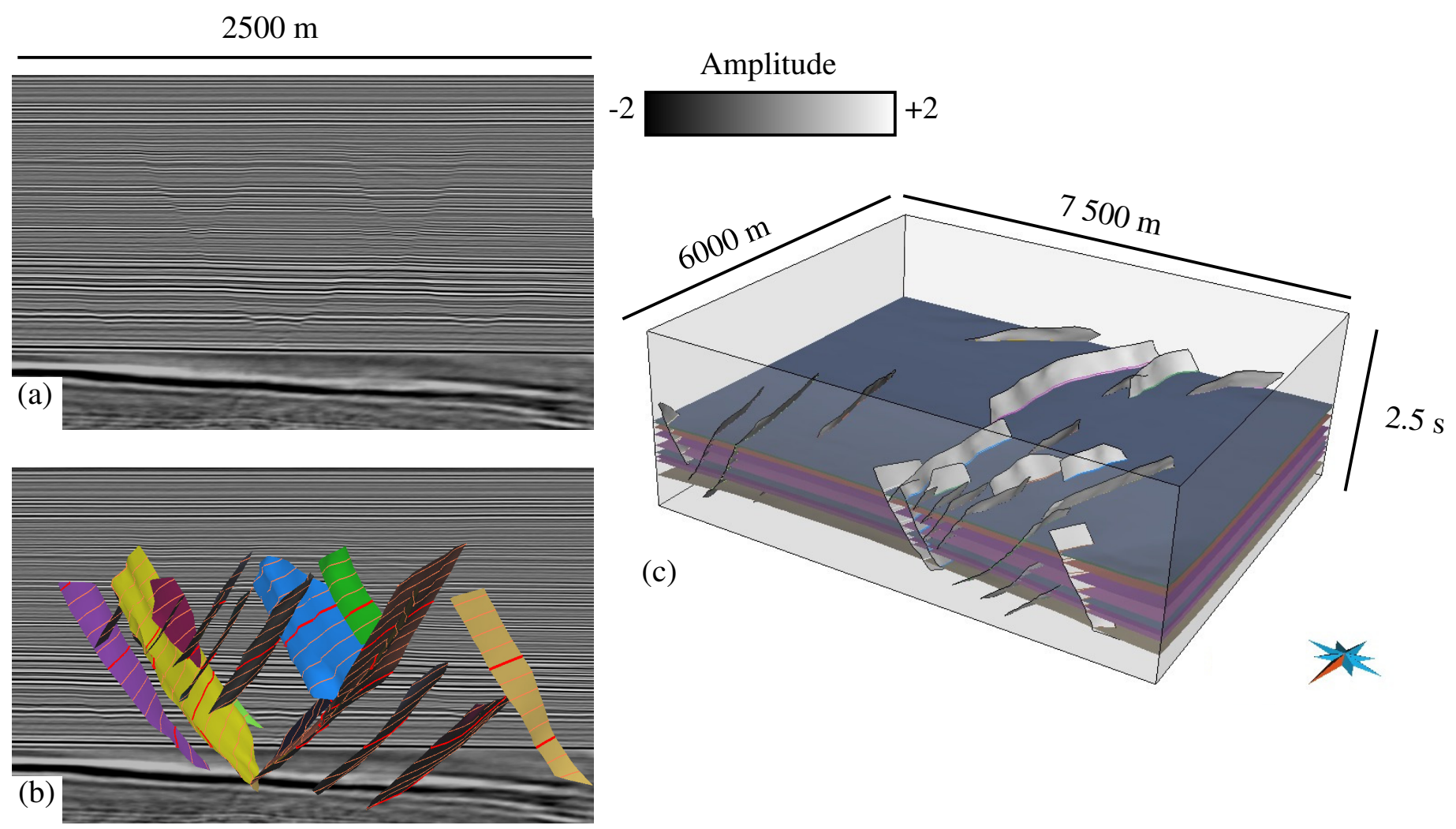

Figure 9: Reference structural model of a faulted area in the Santos basis, offshore Brazil. (a) Input high resolution seismic data and (b) constructed fault network. (c) Constructed structural model.

\section{Generation of synthetic sparse data}

We sliced the reference model to generate 25 synthetic $2 \mathrm{D}$ cross-sections. The synthetic cross-sections are perpendicular to the main fault orientation. The obtained cross-sections make up a sparse data set to reflect uncertainties that would exist using $2 \mathrm{D}$ seismic imaging. They were used as input for kinematic and implicit modeling reconstruction.

\section{Reconstruction using interpolation and kine- matic modeling}

From the synthetic cross-sections, a fault network composed of elliptical surfaces was reconstructed. The fault center was placed at the barycenter of the interpreted fault traces. The fault height and length were automatically deduced from the fault observations. The fault operator width was arbitrarily chosen as $20 \%$ of the length to limit overlapping between several operator volumes. Both modeling methods (implicit surface interpolation and our kinematic workflow) were then used to reconstruct two horizon models. For the interpolation, we did not use fault type information (which forces the throw to be positive or negative for normal and reverse faults, respectively) to highlight the variations between both methods.

\subsection{Comparison results}

We reconstructed several models from different 2D data subsampling (25 cross-sections for Figure 10, 15 cross-sections for Figure 11, and 6 cross-sections for Figure 12). When the model is densely sampled (e.g., using 25 cross-sections) visual inspection shows that the two reconstructed horizon models are fairly similar. In particular, we note that both interpolationbased and kinematic methods reproduce accurately the geometries of the cut-off lines (Figure 10.e,g,h). The major difference is that faults of the constructed models are elliptical while in the reference model they have more rectangular geometries. Our methodology cannot accurately reproduce fault tip-line geometries.

When data are less densely sampled (e.g., 15 crosssections), horizons reconstructed using interpolation may exhibit null-displacement and throw inversions on the fault surface (Figure 11.b,e). Such kinematically inconsistent geometries may be due to horizon picks that cross the fault (Figure 11.g) or to the extrapolation of small-scale displacement variations (Fig- 


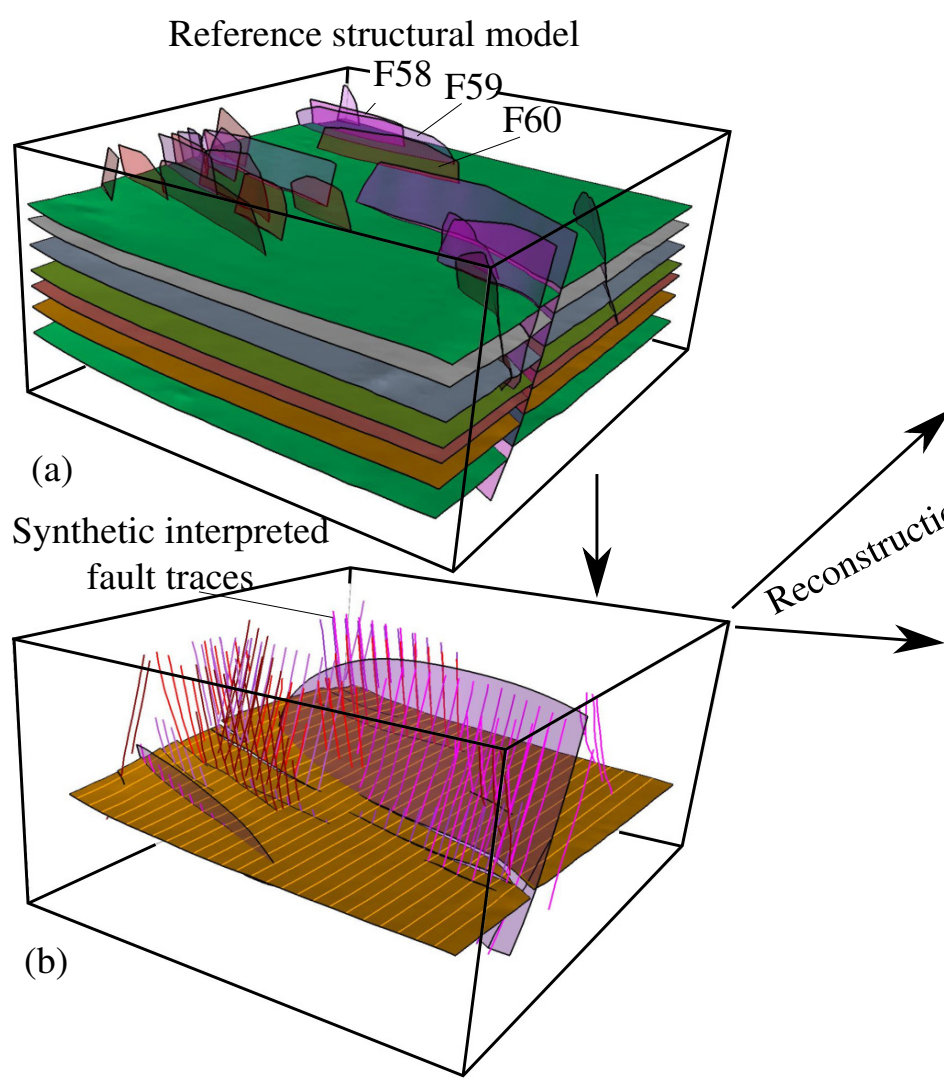

Subsampling and fault geometries reconstruction

Implicit modeling reconstruction
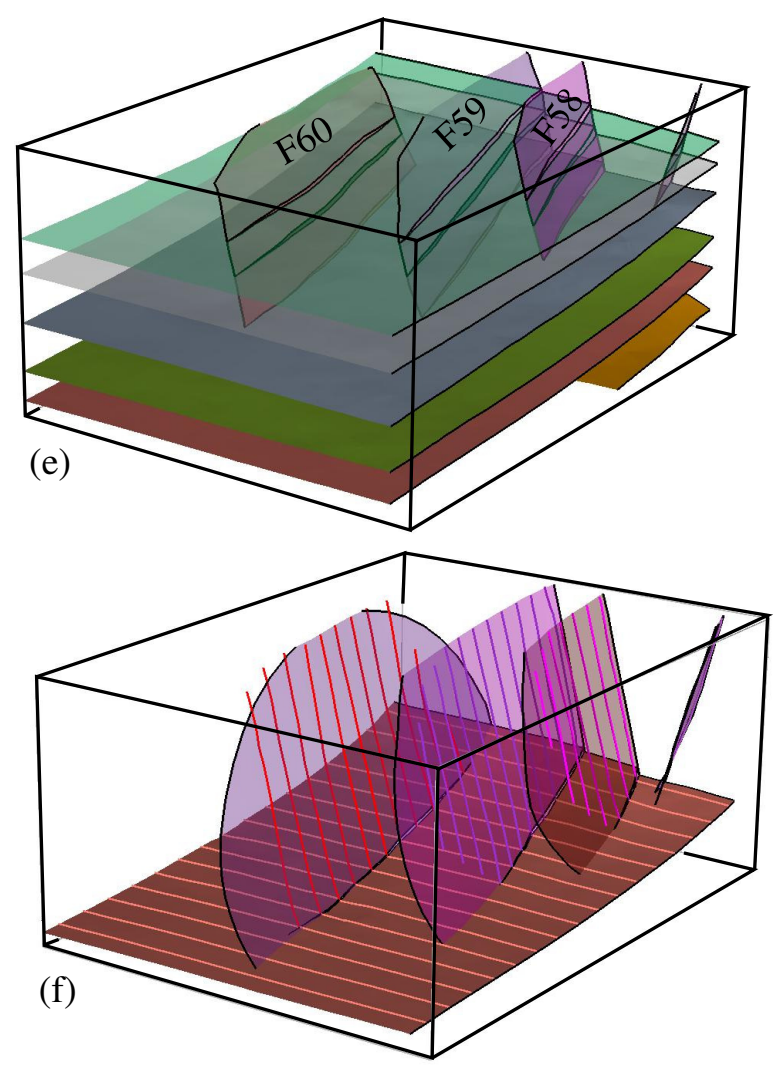

(c)

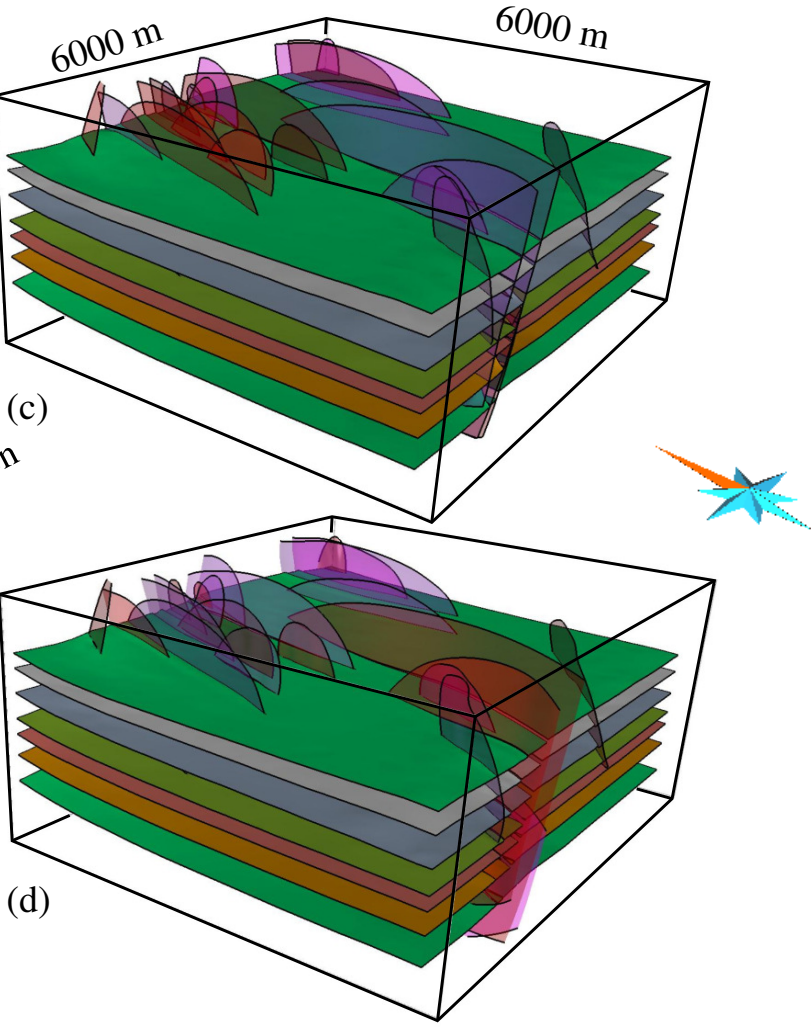

Kinematic reconstruction

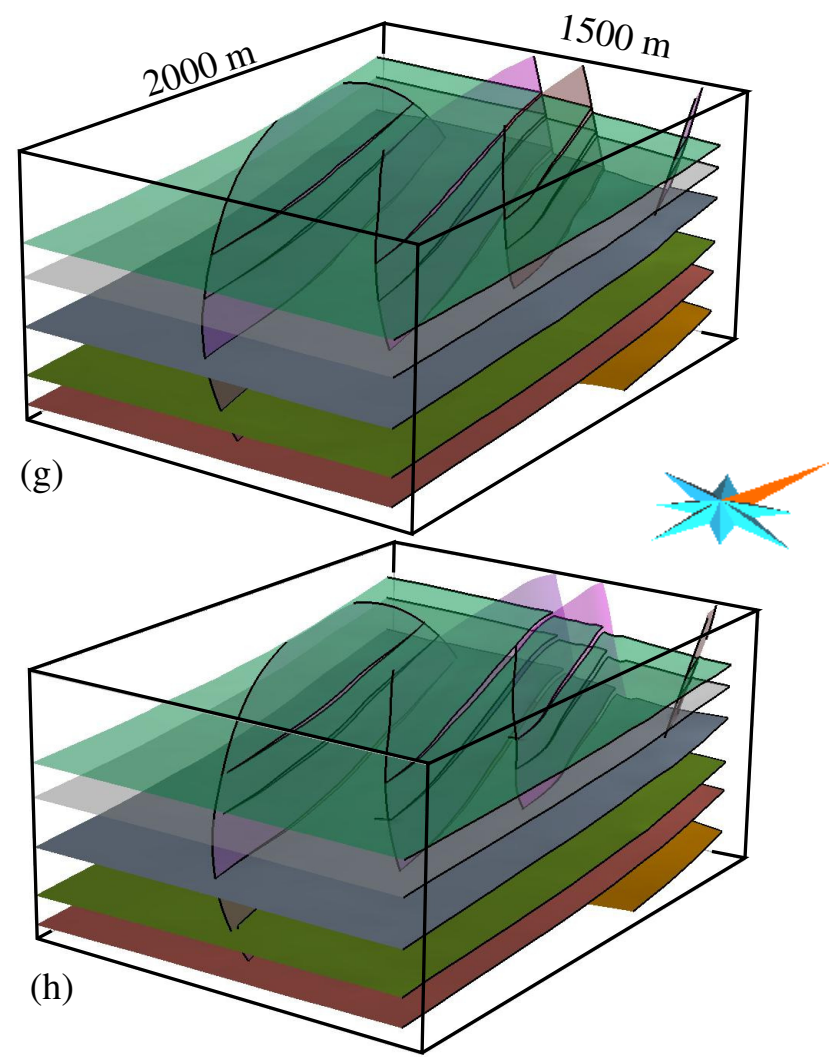

Figure 10: Comparison method for kinematic and geometric modeling. From a reference model (a,e), synthetic cross-sections $(b, f)$ are extracted. The fault geometries are automatically computed from the interpreted fault traces. The horizons are reconstructed using implicit modeling $(\mathrm{c}, \mathrm{g})$ and our kinematic method $(\mathrm{d}, \mathrm{h})$. Both horizon models are then compared together and to the reference model. 
ure 11.h). The kinematic modeling approach generates a slip distribution that respects a theoretical displacement model. Our method is not able to reproduce high-frequency slip variations that can be observed on the reference model (Figure 11.a,d) but the obtained displacement is free of throw inconsistencies and is close to the reference model (Figure 11.c,f).

Figure 12 exhibits a reconstruction from six crosssections. Most of the faults are imaged by only one cross-section (Figure 12.a). We chose to model only the faults imaged by at least two cross-sections (Figure 12.b.c). Otherwise, the comparison would be biased by the way the fault lengths are chosen. For larger faults, the displacement obtained by interpolation are irregular (Figure 12.e). The kinematic method generates smooth displacement profiles and honors the data (Figure 12.f).

\section{Discussion}

We presented a method for controlling fault kinematics while modeling faulted strata. We use a model of the near-fault displacement field whose parameters are chosen within a given geologically acceptable range by numerical optimization. This method limits the risk of building kinematically inconsistent models. It was successfully tested on a reference structural model from the Santos Basin (offshore Brazil) built from highresolution seismic data.

The introduction of kinematic control requires the addition of several modeling parameters (e.g., fault operator volume width and optimizer parameters). The choice of these parameters by the modeler, along with the time spent optimizing the kinematic parameters for each fault increase the time to obtain a model. As a result, in the presented case-study, our method is slower than interpolation. However, the obtained models are kinematically consistent and structural validation is made easier, reducing the time spent in the loop between structural interpretation, 3D-modeling and validation. Also, such an iterative solution is often not reproducible if the study is reconducted, whereas the kinematic method makes it easier to reproduce the results.

Figure 7 illustrates the ability of our fault operator to handle a wide range of fault types. However, in the present work the optimization scheme is only demonstrated for displacement patterns typical of isolated faults. Dealing with more complex displacement patterns, by using more complex displacement profiles, has to be further tested. This would increase the num- ber of control points and derivative values describing the throw profiles that need to be optimized. Further developments are thus required to handle complex deformation styles, including fault branching, reverse faults, and non-elliptical or segmented normal faults with several displacement maxima.

In our workflow, the choice of fault geometry precedes the setting of kinematic parameters. It is often necessary to modify fault dimensions and location to find a suitable kinematic parameterization. Among the required geometric parameters, choosing the width of the fault operator is uncertain. Choosing the operator width (or the other geometric parameters) within the optimization loop is not efficient in practice because this requires the reinterpolation of the continuous horizon geometries each time the misfit function is evaluated. This is why the choice of the width of the fault operator remains a user choice in our implementation. Searching for scaling laws between the operator width, the fault length and the maximum slip at the fault center is a future objective of this project. This remark relates also to the physical meaning of the discontinuous displacement field: as interpretation only provides access to the final deformed state, the separation of the displacement into two distinct components is non-unique (Figure 13). In our work, the attenuation profile clearly depends on how the continuous stratigraphy was obtained in the first place (Figure 13). Therefore the proposed model is mainly a convenience to obtain and update stratigraphic geometry in the vicinity of faults. Physical interpretation of this model should consider the total deformation field, and rely on more detailed kinematic or geomechanical analyzes.

\section{Conclusions}

We presented a kinematic modeling workflow where a consistent fault-related displacement is added directly to the horizon model. Instead of updating the fault slip by manually modifying interpolation constraint points close to the fault, the fault kinematics construction is guided by a $3 \mathrm{D}$ numerical fault object and automated through numerical optimization. In the second section of this paper, we show that our method can limit the risk of producing slip inversion, and null slip far from observation data, which are kinematically inconsistent. We argue that our kinematic modeling method is beneficial when structural data quality is poor, and when the deformation style is known a priori. 
Example 1

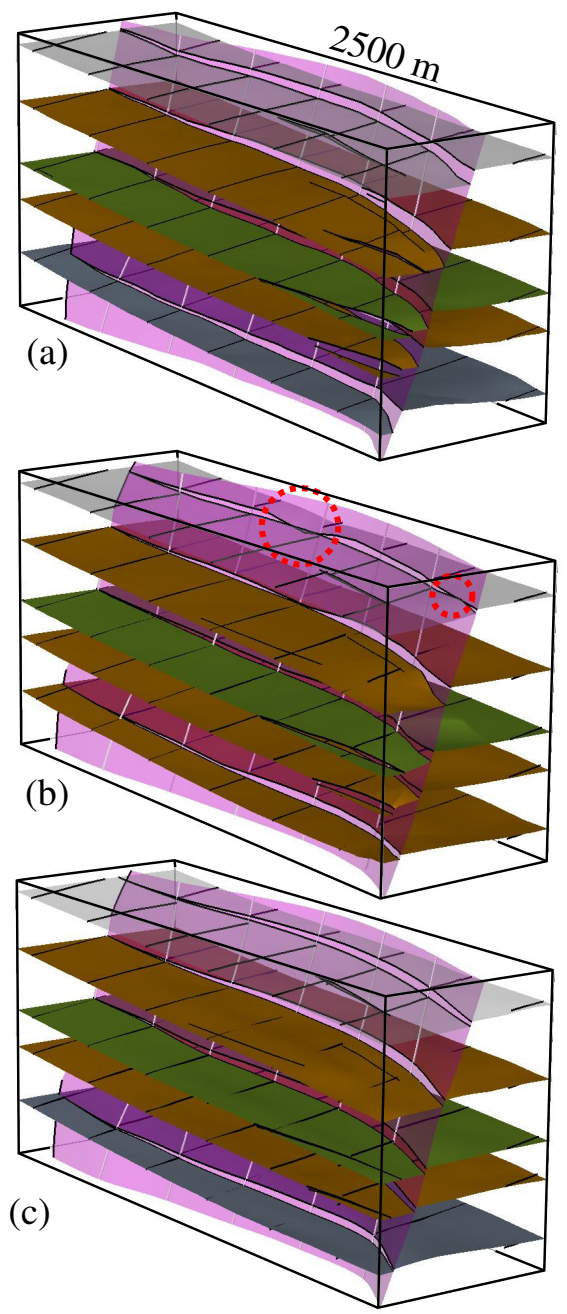

(d)

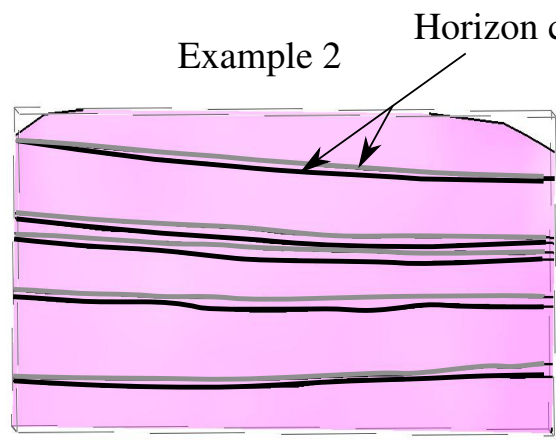

Reference model

(e)

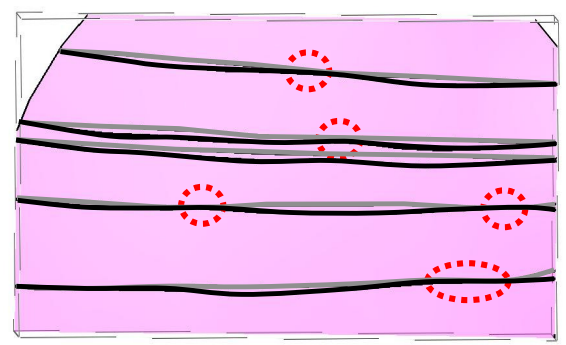

Implicit modeling reconstruction

(f)

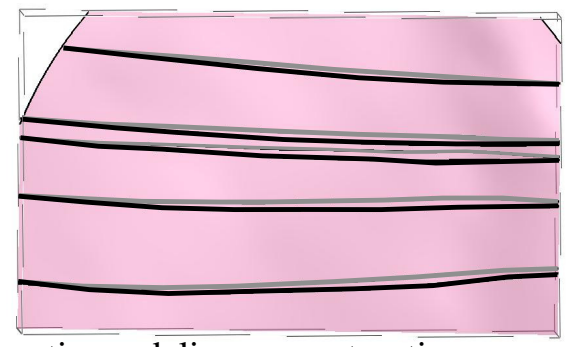

(g)

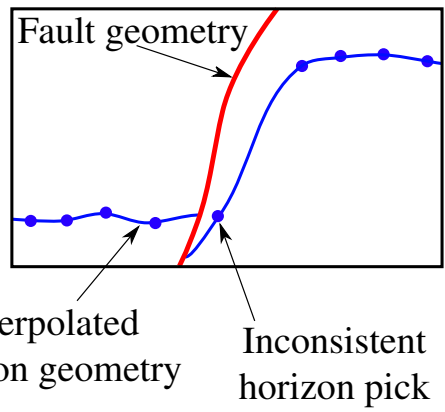

(h)

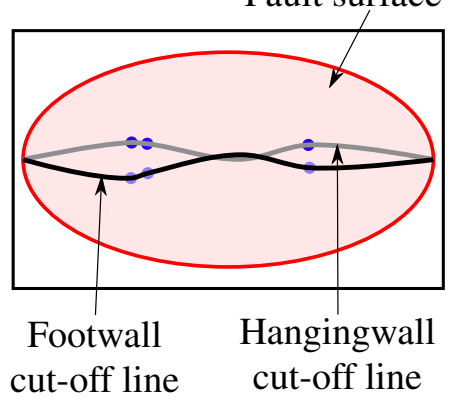

Kinematic modeling reconstruction

Figure 11: Examples of how the fault operator may help to generate more realistic models when modeling from sparse data (15 cross-sections). Throw inversions and null displacements are highlighted by red circles on the horizon models built using interpolation only (b,e). These inconsistencies are not present on the initial model $(\mathrm{a}, \mathrm{d})$ and are not generated when using our kinematic workflow $(\mathrm{c}, \mathrm{f})$. They may be due to horizon picks located on the wrong size of the fault $(\mathrm{g})$ or due to the sparsity of the data $(\mathrm{h})$. 
(a)

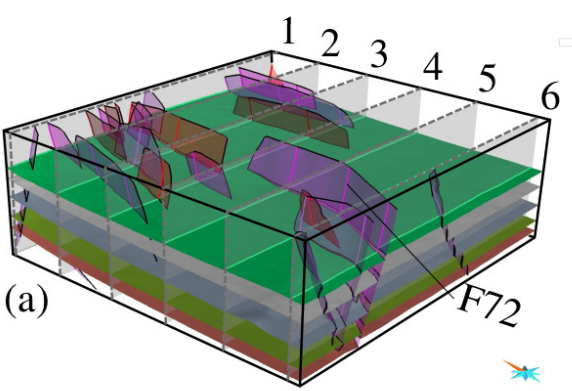

Reference model and synthetic 2D cross-sections

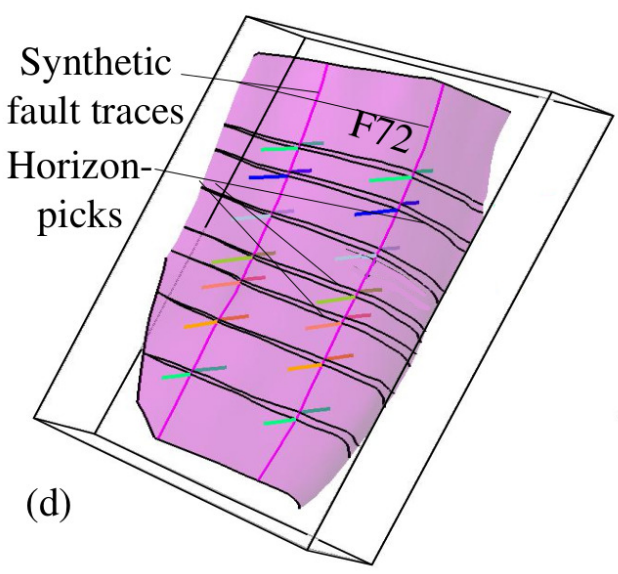

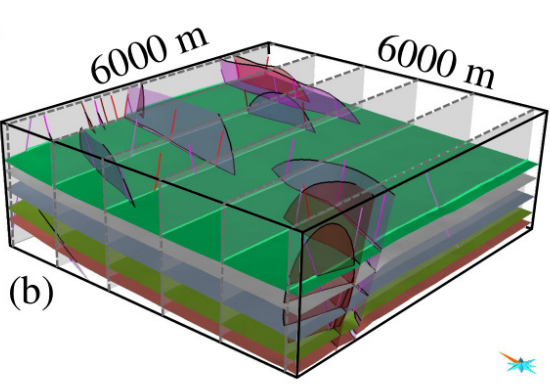

Implicit modeling

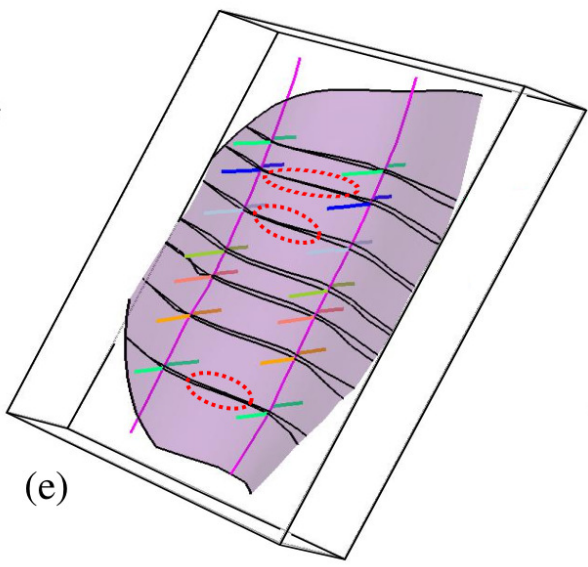

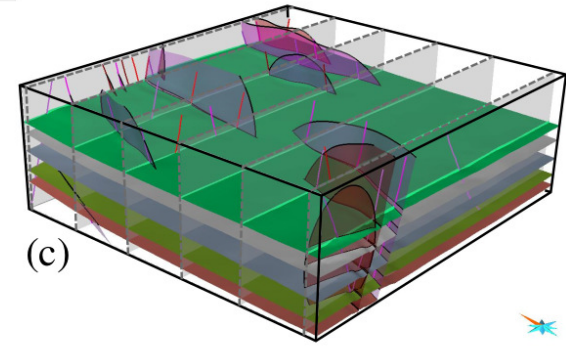

Kinematic modeling

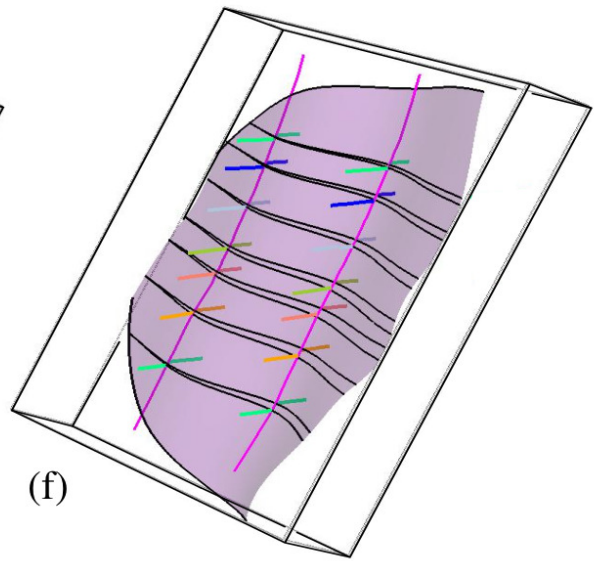

Figure 12: Reconstruction from six synthetic cross-sections. (a,d) Reference model and synthetic sparse data. Due to the gaps between cross-sections, most of the small faults are not reconstructed. Models reconstructed using implicit modeling (b,e) and kinematic modeling $(\mathrm{c}, \mathrm{f})$. Red circles highlight inconsistencies. The kinematic method honors horizon data and produces smooth displacement profiles.

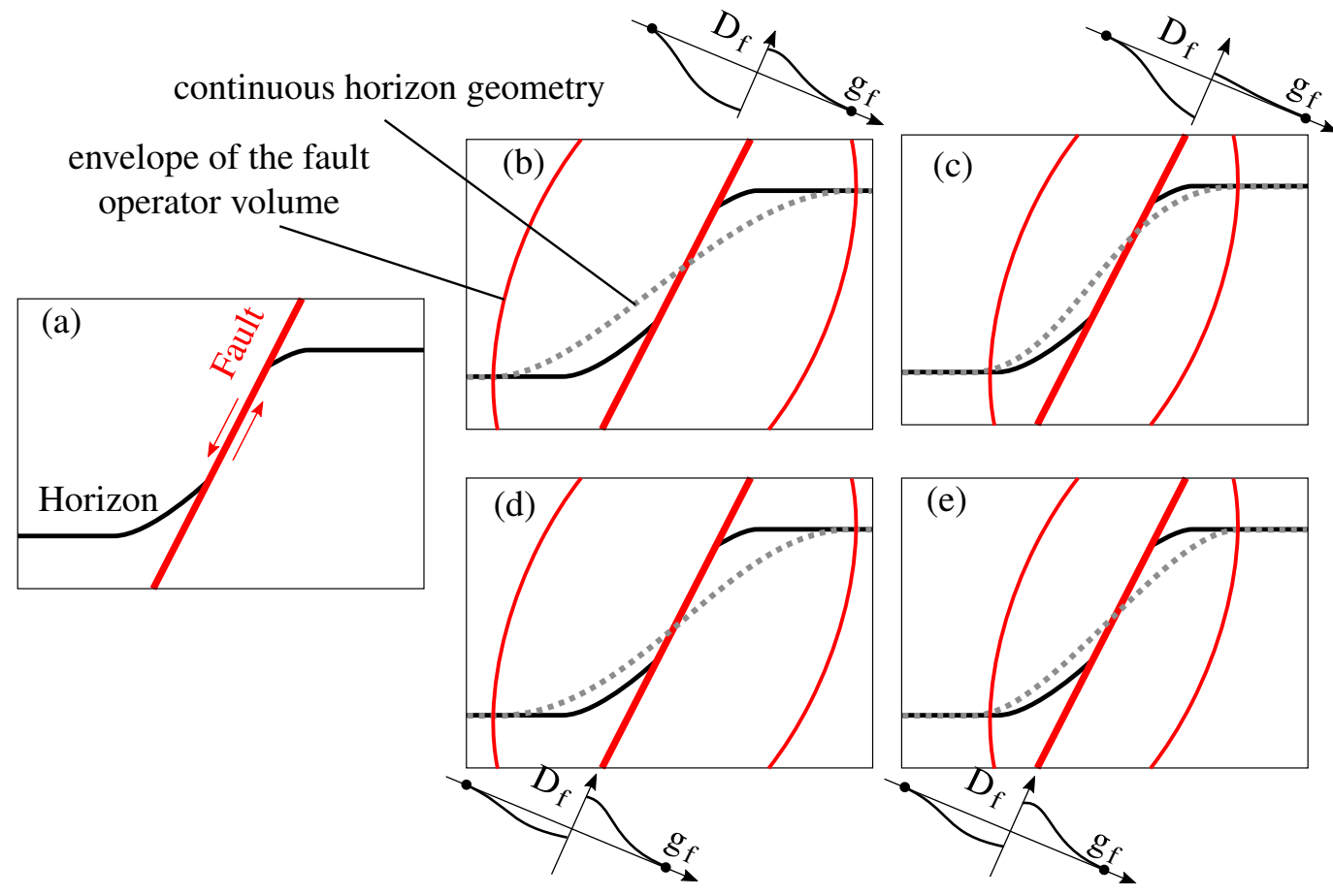

Figure 13: The separation of the deformation between continuous and discontinuous fields is non-unique. Illustrations (b,c,d) and (e) show how the fault structure (a) can be modeled using different operator width and different hypothetical interpolation method. 
Our parametric model of the fault displacement distribution makes it possible to control the structural style while honoring observations. This avoids timeconsuming mechanical simulation where physical parameters can be difficult to choose. As a result, the presented fault operator can be run interactively and could be useful to sketch three-dimensional models and tectonic history (Jessell, 1981; Jackson et al., 2015; Wellmann et al., 2015; Laurent et al., 2015; Godefroy et al., 2017). Our workflow could also be used to assess structural and kinematic uncertainties by looking not only for the best solution to the optimization but also for a set of acceptable solutions (Cardozo et al., 2011), opening the way to a multi-scenario analysis of fault-kinematics and fault-seal properties.

\section{Acknowledgements}

This work was performed in the frame of the RING project at Université de Lorraine and partly funded by the grant Investissements d'avenir Labex RESSOURCES21 (ANR-10-LABX-21-01). We would like to thank for their support the industrial and academic sponsors of the RING-GOCAD Consortium managed by ASGA. Software corresponding to this paper is available to sponsors in the RING software package FaultMod2. We also acknowledge Paradigm for the SKUA-GOCAD Software and API. The authors are grateful to PGS Investigação Petrolífera Limitada for providing the seismic data from the Santos Basin.

\section{References}

Allmendinger, R. W. (1998). Inverse and forward numerical modeling of trishear fault-propagation folds. Tectonics, 17(4):640-656.

Barnett, J. A., Mortimer, J., Rippon, J. H., Walsh, J. J., and Watterson, J. (1987). Displacement geometry in the volume containing a single normal fault. AAPG Bulletin, 71(8):925-937.

Baudon, C. and Cartwright, J. A. (2008). 3D seismic characterisation of an array of blind normal faults in the Levant Basin, Eastern Mediterranean. Journal of Structural Geology, 30(6):746-760.

Berg, S. S. and Skar, T. (2005). Controls on damage zone asymmetry of a normal fault zone: outcrop analyses of a segment of the moab fault, se utah. Journal of Structural Geology, 27(10):1803-1822.
Botter, C., Cardozo, N., Hardy, S., Lecomte, I., and Escalona, A. (2014). From mechanical modeling to seismic imaging of faults: A synthetic workflow to study the impact of faults on seismic. Marine and Petroleum Geology, 57:187-207.

Botter, C., Cardozo, N., Lecomte, I., Rotevatn, A., and Paton, G. (2017). The impact of faults and fluid flow on seismic images of a relay ramp over production time. Petroleum Geoscience, 23(1):1728.

Cardozo, N. and Aanonsen, S. (2009). Optimized trishear inverse modeling. Journal of Structural Geology, 31(6):546-560.

Cardozo, N. and Brandenburg, J. (2014). Kinematic modeling of folding above listric propagating thrusts. Journal of Structural Geology, 60:1-12.

Cardozo, N., Jackson, C. A.-L., and Whipp, P. S. (2011). Determining the uniqueness of best-fit trishear models. Journal of Structural Geology, 33(6):1063-1078.

Caumon, G., Gray, G., Antoine, C., and Titeux, M.O. (2013a). Three-dimensional implicit stratigraphic model building from remote sensing data on tetrahedral meshes: theory and application to a regional model of La Popa Basin, NE Mexico. IEEE Transactions on Geoscience and Remote Sensing, 51(3):1613-1621.

Caumon, G., Laurent, G., Pellerin, J., Cherpeau, N., Lallier, F., Merland, R., and Bonneau, F. (2013b). Current bottlenecks in geomodeling workflows and ways forward. Closing the Gap: Advances in Applied Geomodeling for Hydrocarbon Reservoirs. CSPG Memoir, 20:43-52.

Chapman, T. and Meneilly, A. (1990). Fault displacement analysis in seismic exploration. First Break, $8(1): 11-22$.

Childs, C., Manzocchi, T., Walsh, J. J., Bonson, C. G., Nicol, A., and Schöpfer, M. P. (2009). A geometric model of fault zone and fault rock thickness variations. Journal of Structural Geology, 31(2):117-127.

Choi, J.-H., Edwards, P., Ko, K., and Kim, Y.-S. (2016). Definition and classification of fault damage zones: A review and a new methodological approach. Earth-Science Reviews, 152:70-87. 
Coelho, S., Passchier, C., and Grasemann, B. (2005). Geometric description of flanking structures. Journal of Structural Geology, 27(4):597-606.

Eberhart, R. C. and Kennedy, J. (1995). A new optimizer using particle swarm theory. In Proceedings of the sixth international symposium on micro machine and human science, volume 1, pages 39-43. New York, NY.

Fossen, H. (2016). Structural geology. Cambridge University Press.

Freeman, B., Boult, P. J., Yielding, G., and Menpes, S. (2010). Using empirical geological rules to reduce structural uncertainty in seismic interpretation of faults. Journal of Structural Geology, 32(11):16681676.

Freeman, B., Yielding, G., and Badley, M. (1990). Fault correlation during seismic interpretation. First Break, 8(3):87-95.

Freitag, U., Sanderson, D., Lonergan, L., and Bevan, T. (2017). Comparison of upwards splaying and upwards merging segmented normal faults. Journal of Structural Geology, 100:1-11.

Georgsen, F., Røe, P., Syversveen, A. R., and Lia, O. (2012). Fault displacement modelling using 3D vector fields. Computational Geosciences, 16(2):247259 .

Giba, M., Walsh, J., and Nicol, A. (2012). Segmentation and growth of an obliquely reactivated normal fault. Journal of Structural Geology, 39:253-267.

Godefroy, G., Laurent, G., Caumon, G., and Walter, B. (2017). A Parametric Unfault-and-refault Method for Chronological Structural Modeling. In 79th EAGE Conference and Exhibition 2017. EAGE.

Grasemann, B., Martel, S., and Passchier, C. (2005). Reverse and normal drag along a fault. Journal of Structural Geology, 27(6):999-1010.

Hale, D. (2013). Methods to compute fault images, extract fault surfaces, and estimate fault throws from 3D seismic images. Geophysics, 78(2):O33-O43.

Holden, L., Mostad, P., Nielsen, B. F., Gjerde, J., Townsend, C., and Ottesen, S. (2003). Stochastic structural modeling. Mathematical Geology, 35(8):899-914.
Hollund, K., Mostad, P., Nielsen, B. F., Holden, L., Gjerde, J., Contursi, M. G., McCann, A. J., Townsend, C., and Sverdrup, E. (2002). Havana a fault modeling tool. Norwegian Petroleum Society Special Publications, 11:157-171.

Iacopini, D., Butler, R., Purves, S., McArdle, N., and De Freslon, N. (2016). Exploring the seismic expression of fault zones in 3D seismic volumes. Journal of Structural Geology, 89:54-73.

Jackson, C. A.-L., Bell, R. E., Rotevatn, A., and Tvedt, A. B. (2017). Techniques to determine the kinematics of synsedimentary normal faults and implications for fault growth models. Geological Society, London, Special Publications, 439:SP439-22.

Jackson, C. A.-L. and Rotevatn, A. (2013). 3D seismic analysis of the structure and evolution of a saltinfluenced normal fault zone: a test of competing fault growth models. Journal of Structural Geology, 54:215-234.

Jackson, M., Hampson, G., Rood, D., Geiger, S., Zhang, Z., Sousa, M., Amorim, R., Vital Brazil, E., Samavati, F., and Guimaraes, L. (2015). Rapid reservoir modeling: Prototyping of reservoir models, well trajectories and development options using an intuitive, sketch-based interface. In SPE Reservoir Simulation Symposium. Society of Petroleum Engineers.

Jessell, M. (1981). Noddy: an interactive map creation package. Unpublished MSc Thesis, University of London.

Johri, M., Zoback, M. D., and Hennings, P. (2014). A scaling law to characterize fault-damage zones at reservoir depths. AAPG Bulletin, 98(10):2057-2079.

Jolley, S., Dijk, H., Lamens, J., Fisher, Q., Manzocchi, T., Eikmans, H., and Huang, Y. (2007). Faulting and fault sealing in production simulation models: Brent Province, northern North Sea. Petroleum Geoscience, 13(4):321-340.

Kim, Y.-S. and Sanderson, D. J. (2005). The relationship between displacement and length of faults: a review. Earth-Science Reviews, 68(3):317-334.

Laurent, G., Caumon, G., Bouziat, A., and Jessell, M. (2013). A parametric method to model 3D displacements around faults with volumetric vector fields. Tectonophysics, 590:83-93. 
Laurent, G., Caumon, G., and Jessell, M. (2015). Interactive editing of 3D geological structures and tectonic history sketching via a rigid element method. Computers \& Geosciences, 74:71-86.

Liang, L., Hale, D., Maucec, M., et al. (2010). Estimating fault displacements in seismic images. In 2010 SEG Annual Meeting. Society of Exploration Geophysicists.

Machado, G., Alali, A., Hutchinson, B., Olorunsola, O., and Marfurt, K. J. (2016). Display and enhancement of volumetric fault images. Interpretation.

Maerten, F. and Maerten, L. (2015). On a method for reducing interpretation uncertainty of poorly imaged seismic horizons and faults using geomechanically based restoration technique. Interpretation, 3(4):105-116.

Magee, C., Duffy, O. B., Purnell, K., Bell, R. E., Jackson, C. A.-L., and Reeve, M. T. (2015). Faultcontrolled fluid flow inferred from hydrothermal vents imaged in 3D seismic reflection data, offshore NW Australia. Basin Research, 1:20.

Manzocchi, T., Childs, C., and Walsh, J. (2010). Faults and fault properties in hydrocarbon flow models. Geofluids, 10(1-2):94-113.

Mukherjee, S. (2014). Review of flanking structures in meso- and micro-scales. Geological Magazine, 151(06):957-974.

Mulchrone, K. F. (2007). Modelling flanking structures using deformable high axial ratio ellipses: Insights into finite geometries. Journal of Structural Geology, 29(7):1216-1228.

Munthe, K., Holden, L., Mostad, P., and Townsend, C. (1994). Modelling sub-seismic fault patterns using a marked point process. In ECMOR IV-4th European Conference on the Mathematics of Oil Recovery.

Nicol, A., Watterson, J., Walsh, J., and Childs, C. (1996). The shapes, major axis orientations and displacement patterns of fault surfaces. Journal of Structural Geology, 18(2):235-248.

Nixon, C. W., Sanderson, D. J., and Bull, J. M. (2011). Deformation within a strike-slip fault network at Westward Ho!, Devon UK: Domino vs conjugate faulting. Journal of Structural Geology, 33(5):833843.
Nixon, C. W., Sanderson, D. J., Dee, S. J., Bull, J. M., Humphreys, R. J., and Swanson, M. H. (2014). Fault interactions and reactivation within a normal-fault network at Milne Point, Alaska. AAPG Bulletin, 98(10):2081-2107.

Osagiede, E. E., Duffy, O. B., Jackson, C. A.-L., and Wrona, T. (2014). Quantifying the growth history of seismically imaged normal faults. Journal of Structural Geology, 66:382-399.

Peacock, D. (2002). Propagation, interaction and linkage in normal fault systems. Earth-Science Reviews, 58(1):121-142.

Peacock, D. and Sanderson, D. (1991). Displacements, segment linkage and relay ramps in normal fault zones. Journal of Structural Geology, 13(6):721-733.

Qi, J., Machado, G., and Marfurt, K. (2017). A workflow to skeletonize faults and stratigraphic features. Geophysics, 82(4):O57-O70.

Richards, F. L., Richardson, N. J., Bond, C. E., and Cowgill, M. (2015). Interpretational variability of structural traps: implications for exploration risk and volume uncertainty. Geological Society, London, Special Publications, 421(1):7-27.

Rivenæs, J. C., Otterlei, C., Zachariassen, E., Dart, C., and Sjøholm, J. (2005). A 3D stochastic model integrating depth, fault and property uncertainty for planning robust wells, Njord Field, offshore Norway. Petroleum Geoscience, 11(1):57-65.

Roberts, G. P. (1996). Variation in fault-slip directions along active and segmented normal fault systems. Journal of Structural Geology, 18(6):835-845.

Roberts, G. P. and Ganas, A. (2000). Fault-slip directions in central and southern Greece measured from striated and corrugated fault planes: Comparison with focal mechanism and geodetic data. Journal of Geophysical Research: Solid Earth, 105(B10):2344323462.

Sibson, R. (1977). Fault rocks and fault mechanisms. Journal of the Geological Society, 133(3):191-213.

Spahić, D., Grasemann, B., and Exner, U. (2013). Identifying fault segments from 3D fault drag analysis (Vienna Basin, Austria). Journal of Structural Geology, 55:182-195. 
Thore, P., Shtuka, A., Lecour, M., Ait-Ettajer, T., and Cognot, R. (2002). Structural uncertainties: Determination, management, and applications. Geophysics, 67(3):840-852.

Torabi, A. and Berg, S. S. (2011). Scaling of fault attributes: A review. Marine and Petroleum Geology, 28(8):1444-1460.

Tvedt, A. B., Rotevatn, A., and Jackson, C. A. (2016). Supra-salt normal fault growth during the rise and fall of a diapir: Perspectives from 3D seismic reflection data, Norwegian North Sea. Journal of Structural Geology.

Tvedt, A. B., Rotevatn, A., Jackson, C. A.-L., Fossen, H., and Gawthorpe, R. L. (2013). Growth of normal faults in multilayer sequences: A $3 \mathrm{D}$ seismic case study from the Egersund Basin, Norwegian North Sea. Journal of Structural Geology, 55:1-20.

Walsh, J. and Watterson, J. (1987). Distributions of cumulative displacement and seismic slip on a single normal fault surface. Journal of Structural Geology, 9(8):1039-1046.

Walsh, J. J. and Watterson, J. (1988). Analysis of the relationship between displacements and dimensions of faults. Journal of Structural Geology, 10(3):239247.

Walsh, J. J. and Watterson, J. (1989). Displacement gradients on fault surfaces. Journal of Structural Geology, 11(3):307-316.

Weinzierl, W., Schulte, L., and Aarre, V. (2016). Volumetric of fault perturbation in the first Fresnel zone. Interpretation, 4(4):T419-T426.

Wellmann, J., Thiele, S., Lindsay, M., and Jessell, M. (2015). pynoddy 1.0: an experimental platform for automated 3-D kinematic and potential field modelling. Geoscientific Model Development Discussions, 8:10011-10051.

Willemse, E. J. (1997). Segmented normal faults: Correspondence between three-dimensional mechanical models and field data. Journal of Geophysical Research: Solid Earth, 102(B1):675-692.

Wu, X. and Zhu, Z. (2017). Methods to enhance seismic faults and construct fault surfaces. Computers \& Geosciences, 107:37-48. 